\title{
Scaling the impact of sustainability initiatives: a typology of amplification processes
}

\author{
David P. M. Lam" ${ }^{*}$, Berta Martín-López ${ }^{1}$, Arnim Wiek ${ }^{2,3,4}$, Elena M. Bennett ${ }^{5}$, Niki Frantzeskaki', \\ Andra I. Horcea-Milcu ${ }^{7,8,9}$ and Daniel J. Lang ${ }^{1}$
}

\begin{tabular}{l}
\hline * Correspondence: david.lam@ \\
leuphana.de \\
${ }^{1}$ Institute for Ethics and \\
Transdisciplinary Sustainability \\
Research, Faculty of Sustainability, \\
Leuphana University Lüneburg, \\
Universitätsallee 1, 21335 Lüneburg, \\
Germany \\
Full list of author information is \\
available at the end of the article
\end{tabular}

available at the end of the article

\begin{abstract}
Amplifying the impact of sustainability initiatives to foster transformations in urban and rural contexts, has received increasing attention in resilience, social innovation, and sustainability transitions research. We review the literature on amplification frameworks and propose an integrative typology of eight processes, which aim to increase the impact of such initiatives. The eight amplification processes are: stabilizing, speeding up, growing, replicating, transferring, spreading, scaling up, and scaling deep. We aggregated these processes into three categories: amplifying within, amplifying out, and amplifying beyond. This integrative typology aims to stimulate the debate on impact amplification from urban and rural sustainability initiatives across research areas to support sustainability transformations. We propose going beyond an understanding of amplification, which focuses only on the increase of numbers of sustainability initiatives, by considering how these initiatives create transformative change.
\end{abstract}

Keywords: City, Urban, Rural, Scaling, Transition initiative, Transformation, Transition

\section{Science highlights}

- We suggest a typology of processes amplifying the impact of sustainability initiatives that exist and have impact in urban and rural contexts

- Eight amplification processes are identified in the scientific literature

- Amplification processes are grouped into three categories: amplifying within, out, and beyond

- The typology conceptually bridges research areas with the aim to initiate dialogue on sustainability transformations

\section{Practice recommendations}

- Sustainability initiatives in urban and rural contexts increase their impact through one or more of our eight identified amplification processes

(c) The Author(s). 2020 Open Access This article is licensed under a Creative Commons Attribution 4.0 International License, which permits use, sharing, adaptation, distribution and reproduction in any medium or format, as long as you give appropriate credit to the original author(s) and the source, provide a link to the Creative Commons licence, and indicate if changes were made. The images or other third party material in this article are included in the article's Creative Commons licence, unless indicated otherwise in a credit line to the material. If material is not included in the article's Creative Commons licence and your intended use is not permitted by statutory regulation or exceeds the permitted use, you will need to obtain permission directly from the copyright holder. To view a copy of this licence, visit http://creativecommons.org/licenses/by/4.0/. 
- Sustainability initiatives should apply a set of amplification processes to foster transformative change

- Increasing impact can also be achieved by changing values and mind-sets, referred to as 'scaling deep'

\section{Introduction}

Scientists, politicians, entrepreneurs, and civil society are increasingly calling for sustainability transformations. ${ }^{1}$ This is to ensure that society can operate within the earth's biophysical limits while simultaneously fostering justice and wellbeing (Raskin et al. 2002; Rockström et al. 2009; Westley et al. 2011; Olsson et al. 2014). Sustainability transformations are fundamental changes of interactions and feedbacks in, for example, social-ecological or sociotechnical systems towards sustainability (Gunderson and Holling 2002; Walker et al. 2004; Grin et al. 2010; Olsson et al. 2014). Examples are the shift from cattle ranching to ecotourism based on wildlife in Zimbabwe (Cumming 1999), or Germany's energy transition (Geels et al. 2016). Over the last two decades, sustainability transformations have been addressed in a variety of research areas including resilience (Gunderson and Holling 2002), social innovation (Westley et al. 2006), and sustainability transitions studies (Grin et al. 2010). During the last years, these research areas have come closer together, as they all have a joint interest in societal change towards sustainability. We refer to this emerging literature here as sustainability transformations research (Olsson et al. 2014; Pereira et al. 2015; Loorbach et al. 2017; Avelino et al. 2019; Horcea-Milcu et al. 2020).

Sustainability transformations research is heterogeneous, because of the diverse above-mentioned research areas that investigate transformations with different theories and methods (Loorbach et al. 2017). Despite this heterogeneity, the literature is predominantly led by researchers in the Global North, often with technocratic and positivistic paradigms of what transformations are and how they emerge (Ramos-Mejía et al. 2018; Köhler et al. 2019; Lam et al. 2020). A recent study from the Global South emphasises that transformations are highly contested and an integral part is to consider conflict and dilemmas in the research design early on (Pereira et al. 2020). Furthermore, the normative goal of sustainability is sometimes critiqued to be dominated by Western worldviews, mind-sets, and values, which may not apply to contexts in the Global South (Kothari et al. 2014; Scoones et al. 2020).

In this paper, we examine the literature on sustainability transformations, but do not take any single theoretical or normative concept as the only truth. Instead, we argue that there are multiple understandings of transformations, for example, from different research areas, or different knowledge systems (e.g., scientific, indigenous and local knowledge systems) (Blythe et al. 2018; Lam et al. 2020). Therefore, we highlight that urban and rural sustainability transformations may be best understood when considering them as place-based societal changes driven by local actors. This includes the development and implementation of sustainability initiatives by local actors that realise local and global worldviews, mind-sets, and values (Horcea-Milcu et al. 2019; Lam et al. 2019).

\footnotetext{
${ }^{1}$ Here, we use the term sustainability transformations also as a synonym for sustainability transitions, such as in Loorbach et al. (2017). Although both terms refer to large-scale societal change, we are aware of the nuanced differences that they entail. For a detailed analysis of the similarities and differences of these terms, see Hölscher et al. (2018).
} 
Sustainability initiatives are potential local solutions to sustainability problems with global relevance (e.g., biodiversity loss, health, mobility). These are often designed, carried out, and led by local actors. Sustainability initiatives provide new ways of thinking, doing, and organising (e.g., social, technological, economic, socio-technical, or socialecological). This may be, for example, projects, products, practices, approaches, or technologies (Bennett et al. 2016; Gorissen et al. 2018). Their focus depends on the context and agency (e.g., individual or collective), and can be, for example, on urban agroecology, climate smart cities, or green design (Pereira et al. 2018). Sustainability initiatives are crucial for transformations because they can over time coalesce to shift dominant regimes onto more sustainable pathways and thus foster transformative change (Pereira et al. 2018; Lam et al. 2019). Different research areas refer to sustainability initiatives with unique terms such as grassroots innovations (Seyfang and Smith 2007), seeds of a good Anthropocene (Bennett et al. 2016), social innovations (Westley and Antadze 2010; Moore et al. 2015), transition experiments (Caniglia et al. 2017; Sengers et al. 2019), and transition initiatives (Frantzeskaki et al. 2016; Gorissen et al. 2018). In this paper, we use the term "sustainability initiative" as an umbrella concept for all.

With regard to initiatives, sustainability transformations research generally discusses the beneficial context-settings through which they emerge and flourish (Leach et al. 2012; Smith and Raven 2012), and the approaches of "scaling", i.e., amplification processes that increase their impact (Westley et al. 2011; Moore et al. 2015; Gorissen et al. 2018). Amplification processes describe diverse actions deployed by sustainability initiatives together with other actors (e.g., from government, business, or society) to purposively increase their transformative impact (e.g., initiating a new initiative in another city). The emphasis is thus on the extended impact of initiatives, which is created when new ways of thinking, doing, and organizing things (e.g., practices, processes, or products) get adopted and amplified (Leach et al. 2012; Wigboldus et al. 2016). Understanding amplification processes sheds light on the conditions required, and thus options for purposive interventions, to support such processes (Wiek and Lang 2016). In this paper, we deliberately use the term amplification instead of "scaling" to reduce confusion, because "scaling" suggests the involvement of a "scale" or "higher level" to increase impact (Cash et al. 2006). However, increasing impact of initiatives does not exclusively involve levels or scales (e.g., of governance or quantity). It can, for example, also involve changing values and mind-sets (Horcea-Milcu et al. 2019).

We aspire to bring coherence to the dispersed literature on amplification processes applied by sustainability initiatives to foster transformations. Additionally, we hope to stimulate debate by providing an integrative typology of amplification processes. Scholars from diverse research areas have advanced our understanding of such processes by applying different theories and focusing on different systems of interest, in both urban and rural contexts (van den Bosch and Rotmans 2008; Moore et al. 2015; Olsson et al. 2017). Although some research areas have moved closer to a shared understanding of such processes (Olsson et al. 2017), there is still considerable diversity in how they describe and understand them (Pereira et al. 2015). Diversity is both positive and a challenge. It contributes substantially to diverse debates and empirical insights, but also reduces comparability to draw conclusions, in part, due to a lack of a common language. For example, while certain research areas use similar terms for amplification processes (e.g., scaling out, outscaling) they, in fact, often refer to different processes to 
increase impact. This lack of clarity hinders the advancement of the debate across research areas and the support of sustainability initiatives in selecting processes that increase their impact.

An integrative typology of amplification processes is therefore an important next step for three reasons. First, it will conceptually bridge insights from different research areas. Second, the typology can provide potential insights regarding commonalities and learning within and between research areas, to discuss amplification processes. Third, it can support reflection on current processes with the aim to uncover gaps and challenges as well as points of overlap or divergence in the literature. For example, scholars using different theories and methods could learn from each other. Local actors could inform themselves about how modifying their actions could lead to increasing their impact. Furthermore, policymakers could use the typology to develop policies and institutional spaces that can enable initiatives to amplify their impact.

In this paper, we aim to provide a typology of amplification processes identified in the sustainability transformations literature. First, we introduce the frameworks that discuss amplification processes. Second, we present an integrative typology of amplification processes. We further explain it with examples of sustainability initiatives from urban and rural contexts. Finally, we discuss the relevance, limitations, and implications of the typology for future research.

\section{Amplification frameworks}

Amplification frameworks focus on identifying actions that increase the impact of sustainability initiatives via specific processes. These processes may be referred to as strategies (Moore et al. 2015), mechanisms (van den Bosch and Rotmans 2008; Bennett et al. 2016; Gorissen et al. 2018) or patterns (Naber et al. 2017). Due to the heterogeneity and breadth of the literature, we conducted a selective review that follows the principles of a scoping study (Arksey and O'Malley 2005). Scoping studies map "the key concepts underpinning a research area and the main sources and types of evidence available, (...) especially where an area is complex or has not been reviewed comprehensively before" (Mays et al. 2001). Thus, the review was not exhaustive, but covers contemporary frameworks commonly engaged within the literature (Loorbach et al. 2017).

The selection of frameworks followed two steps. First, based on an explorative reading of relevant literature, we identified sustainability transitions, resilience, and social innovations studies as the three most prominent research areas discussing amplification processes (Olsson et al. 2014; Pereira et al. 2015; Loorbach et al. 2017; Hölscher et al. 2018). Second, by analysing relevant scientific papers from these research areas, we identified frameworks that had a transformative amplification purpose. Due to the scope of the review we excluded frameworks that were mainly descriptive-analytical (e.g., Multi-Level perspective) and only included transformative frameworks (Geels and Schot 2007; Wiek and Lang 2016; Hölscher et al. 2018). While descriptive-analytical frameworks are primarily used to analyse and describe transformations, transformative frameworks are applied to support transformative change (Wiek and Lang 2016). It is important to note that the purpose of the review was not to analyse and compare all amplification frameworks available, but to selectively review those that focus on sustainability transformations (Wigboldus et al. 2016). We intentionally excluded frameworks that did not explicitly focus on 
sustainability, such as diffusion of innovations in general (Rogers 2003) or in organizations (Greenhalgh et al. 2004).

As a result, we identified six frameworks: (1) Strategies for social innovation (Moore et al. 2015), (2) Seeds of a good Anthropocene (Bennett et al. 2016), (3) Scale dynamics (Hermans et al. 2016), (4) Acceleration mechanisms (Gorissen et al. 2018; Ehnert et al. 2018), (5) Transition management (Rotmans and Loorbach 2008; Frantzeskaki et al. 2018), and (6) Strategic niche management (Naber et al. 2017) (Fig. 1, Table 1). Although these frameworks have been used to investigate the amplification of initiatives' impacts in diverse contexts, they are often used to derive empirical insights from initiatives that foster sustainability transformations in urban and rural contexts. For instance, by using the framework of acceleration mechanisms, Gorissen et al. (2018) investigate how diverse types of initiatives (e.g., community currency or bee-friendly city initiatives) contribute to accelerating urban transformations in the City of Genk. Hermans et al. (2016) apply the framework of scale dynamics to discuss the amplification of sustainable agricultural innovations in the Dutch rural region of the Northern Frisian Woodlands. Other frameworks derive insights from initiatives that exist in both urban and rural contexts (Rotmans and Loorbach 2008; Moore et al. 2015; Bennett et al. 2016; Naber et al. 2017). For example, Naber et al. (2017) applied the strategic niche management framework to understand energy initiatives in the city of Zwolle and municipality of Texel in the Netherlands.

The six frameworks derive from three different research areas: social innovations research (Westley et al. 2006), social-ecological transformations research (Gunderson and Holling 2002), and socio-technical transitions research (Grin et al. 2010). These research areas are neither mutually exclusive nor have they been developed separately, and often explicitly refer to or draw from each other (Moore et al. 2015; Hermans et al. 2016; Bennett et al. 2016). Social innovations research focuses on social and institutional entrepreneurship, where leaders of social innovations (e.g., non-profit organizations) try to increase their impact to induce large systems change (Westley et al. 2006;

\begin{tabular}{|c|c|c|c|c|c|c|}
\hline $\begin{array}{l}\text { Amplification } \\
\text { frameworks }\end{array}$ & $\begin{array}{c}\text { Strategies for } \\
\text { social } \\
\text { innovation }\end{array}$ & $\begin{array}{c}\text { Seeds of a } \\
\text { good } \\
\text { Anthropocene }\end{array}$ & $\begin{array}{c}\text { Scale } \\
\text { dynamics }\end{array}$ & $\begin{array}{l}\text { Acceleration } \\
\text { mechanisms }\end{array}$ & $\begin{array}{c}\text { Transition } \\
\text { management }\end{array}$ & $\begin{array}{c}\text { Strategic } \\
\text { niche } \\
\text { management }\end{array}$ \\
\hline \multirow[t]{3}{*}{$\begin{array}{r}\text { Sustainability } \\
\text { initiatives }\end{array}$} & $\begin{array}{c}\text { Social } \\
\text { innovations }\end{array}$ & Seeds & $\begin{array}{l}\text { Grassroots } \\
\text { innovations }\end{array}$ & $\begin{array}{l}\text { Transition } \\
\text { initiatives }\end{array}$ & $\begin{array}{c}\text { Transition } \\
\text { experiments }\end{array}$ & $\begin{array}{c}\text { Transition } \\
\text { experiments }\end{array}$ \\
\hline & Scaling out & Scale up & Outscaling & Replicating & Deepening & Growing \\
\hline & Scaling up & Scale out & Upscaling & Partnering ${ }^{*}$ & Broadening & Replication \\
\hline \multirow[t]{3}{*}{$\begin{array}{r}\text { Amplification } \\
\text { processes }\end{array}$} & Scaling deep & \multirow[t]{3}{*}{ Scale deep } & & Upscaling & Scaling up & $\begin{array}{l}\text { Accumu- } \\
\text { lation }^{\star}\end{array}$ \\
\hline & \multirow[t]{2}{*}{ Cross-cutting ${ }^{*}$} & & & $\begin{array}{l}\text { Instrument- } \\
\text { alising }^{\star}\end{array}$ & & \multirow[t]{2}{*}{$\begin{array}{l}\text { Transform- } \\
\text { ation }\end{array}$} \\
\hline & & & & Embedding & & \\
\hline $\begin{array}{r}\text { Key } \\
\text { reference }\end{array}$ & $\begin{array}{l}\text { Moore et al. } \\
\qquad(2015)\end{array}$ & $\begin{array}{c}\text { Bennett et al. } \\
\text { (2016) }\end{array}$ & $\begin{array}{l}\text { Hermans et al. } \\
\text { (2016) }\end{array}$ & $\begin{array}{c}\text { Gorissen et al. } \\
\text { (2018) }\end{array}$ & $\begin{array}{l}\text { Rotmans and } \\
\text { Loorbach } \\
(2008)\end{array}$ & $\begin{array}{l}\text { Naber et al. } \\
(2017)\end{array}$ \\
\hline \multicolumn{7}{|c|}{ ^ Not used in analysis because this process does not focus specifically on increasing impact. } \\
\hline \multicolumn{7}{|c|}{$\begin{array}{l}\text { Fig. } 1 \text { Overview of amplification frameworks used in sustainability transformation research and their } \\
\text { conceptualization of sustainability initiatives and amplification processes. Note that these are examples of } \\
\text { key references that describe the amplification processes of each framework, but there are many others } \\
\text { discussing the respective processes in the literature (see main text, Tables } 1 \text { and } 2 \text { for further references) }\end{array}$} \\
\hline
\end{tabular}


Table 1 Amplification frameworks

\begin{tabular}{lll}
\hline Framework & Theoretical background & Sustainability initiative \\
\hline $\begin{array}{l}\text { Strategies for } \\
\text { social }\end{array}$ Social innovations research & $\begin{array}{l}\text { Social innovations, i.e. } \\
\text { innovation }\end{array}$ & "initiative, product, program, \\
platform or design that \\
challenges, and over time \\
changes, the defining routines, \\
& & resource and authority flows, \\
& or beliefs of the social system \\
& in which the innovation \\
& occurs" (Moore et al. 2015, p. \\
& 69).
\end{tabular}

\section{Seeds of a Social-ecological good transformations research} Anthropocene (Gunderson and Holling 2002)

Scale dynamics

\section{Social-ecological} transformations research (Gunderson and Holling 2002) and socio-technical transitions research (Grin et al. 2010)

Acceleration mechanisms

Socio-technical transitions research (Grin et al. 2010)
Transition Socio-technical transitions management research (Grin et al. 2010)

$\begin{array}{ll}\text { Strategic } & \text { Socio-technical transitions } \\ \text { niche } & \text { research (Grin et al. 2010) } \\ \text { management } & \end{array}$

Seeds, i.e. "initiatives (social, technological, economic, or social-ecological ways of thinking or doing) that exist, at least in prototype form, and that represent a diversity of worldviews, values, and regions, but are not currently dominant or prominent" (Bennett et al. 2016, p. 442).

Grassroots innovations, i.e. "networks of activists and organizations generating novel bottom-up solutions for sustainable development; solutions that respond to the local situation and the interests and values of the communities involved. [...] [G] rassroots initiatives operate in civil society arenas and involve committed activists experimenting with social innovations as well as using greener technologies." (Seyfang and Smith 2007, p. 585). ${ }^{a}$

Transition initiatives, i.e. "locallybased (...) actor-networks that start-up, adopt and/or engage with new practices, technologies and experiments that seek to profoundly change established unsustainable routines and perceptions towards more sustainable ones." (Gorissen et al. 2018, p. 172)

Transition experiments, i.e. innovation projects "with a societal challenge as a starting point for learning aimed at contributing to a transition." (van den Bosch and Rotmans 2008, p. 12).

Transition experiments, i.e. "inclusive, practice-based and challenge-led initiative designed to promote system innovation through social learning under conditions of uncertainty and ambiguity" (Sengers et al. 2019, p. 161).
Amplification purpose

To "achieve systemic impacts" and "large systems change" (Moore et al. 2015, p. 69). The latter requires combining different types of scaling (Table 2).

To "have transformative impacts beyond initial localities and sectors" (Bennett et al. 2016, p. 443).

To "enact transformative change across scales and have a wider impact beyond the people directly involved in their initial development." (Hermans et al. 2016, p. 285).

To "accelerate sustainability transitions [in city-regions]" (Gorissen et al. 2018, p. 173) innovative contribution to a transition process" (Loorbach 2010, p. 176). This encompasses changing "established ways of thinking (culture), doing (practices) and organizing (structure)" (van den Bosch and Rotmans 2008, p. 5).

To "scale-up and diffuse innovative solutions" in order to increase "the potential of the niche to influence the current regime and eventually achieve a transition." (Naber et al. 2017, p. 344). 
Westley et al. 2014; Moore et al. 2015). This research area focuses on social problems, such as homelessness, poverty, and mental illness (Westley and Antadze 2010). Socialecological transformations research is based on social-ecological systems and resilience studies (Berkes et al. 2000; Gunderson and Holling 2002; Berkes et al. 2003). This research area is concerned about fundamental shifts of human and environmental interactions in complex social-ecological systems (Gunderson and Holling 2002; Berkes et al. 2003; Walker et al. 2004; Olsson et al. 2014), emphasising transformations of governance structures. Socio-technical transitions research is based on science and technology studies as well as evolutionary economics. It is concerned with the replacement of socio-technical regimes, which emerge around dominant technologies, through radical niches, i.e. protected spaces in which path-breaking innovations develop (Grin et al. 2010; Smith and Raven 2012). This research area focuses mainly on transitions towards more sustainable water, mobility, and energy systems in urban and rural contexts (Loorbach et al. 2017).

Former reviews and interdisciplinary work provide detailed insights on commonalities and differences of these research areas (Pereira et al. 2015; Feola 2015; Patterson et al. 2017; Loorbach et al. 2017; Hölscher et al. 2018; Horcea-Milcu et al. 2020; Scoones et al. 2020). For instance, one difference is how these research areas frame their system of interest (Loorbach et al. 2017). Social innovations research focuses on how leaders induce change in social systems (e.g., health care, education, and labour system). Social-ecological transformations research is concerned with the capacity of socialecological systems (e.g., forestry, fisheries, and agriculture system) to respond to disruptive change. Socio-technical transitions research investigates non-linear change in socio-technical systems (e.g., energy, mobility, and water system).

Despite the different theoretical backgrounds, the three research areas all describe sustainability transformations as multilevel, multiphase, and cross-scale processes (Olsson et al. 2014). Commonalities can be found in notions such as path dependencies, regimes, niches, experiments, and governance (Loorbach et al. 2017; Pereira et al. 2018). Furthermore, they all strive to understand how to increase the impact of sustainability initiatives via amplification processes to foster transformations. In the following, we briefly introduce the six frameworks (Fig. 1), with further information for each framework in Table 1, and the process descriptions of each framework in Table 2.

1. Strategies for social innovation research discusses processes to increase the impact of social innovations (Moore et al. 2015). Its main question is how social innovations can contribute to systemic impacts and large systems change (Moore et al. 2015). Large systems change requires a combination of different processes. Moore et al. (2015) describe these processes as scaling out, scaling up, and scaling deep (Table 2).

2. Seeds of a good Anthropocene research discusses processes to spread seeds, which are social, technological, economic, or social-ecological initiatives (Bennett et al. 2016). The purpose for seeds is to spread and have transformative impact beyond their initial context (location or sector) (Bennett et al. 2016). Bennett et al. (2016) describe spreading processes of seeds as scale up, scale out, and scale deep (Table 2). These spreading processes build up on Moore et al. (2015), use similar terms, but describe processes differently since this framework has a different understanding of sustainability initiatives. 
Table 2 Amplification processes from the different frameworks ( ${ }^{*}$ Not used in analysis because this process does not focus specifically on increasing impact)

\begin{tabular}{ll}
\hline Framework & Amplification process \\
\hline Strategies for social & Scaling out \\
innovation & To impact greater numbers of people or communities. Scaling out consists of two \\
& strategies: 1. "Deliberate replication. Replicating or spreading programmes \\
& geographically and to greater numbers while protecting the fidelity and integrity of \\
& the innovation" (Moore et al. 2015, p. 77). 2. "Spreading principles. Disseminate \\
& principles, but with an adaptation to new contexts via co-generation of knowledge, \\
& leveraging social media and learning platforms: 'open scaling'" (Moore et al. 2015, p. \\
& 77). Open scaling means spreading "the core principles and approach of the \\
& innovation [...], leaving it to the local community to adapt it to local conditions" \\
& (Moore et al. 2015, p. 78).
\end{tabular}

\section{Scaling up}

To impact "higher levels of institutions through policy change" (Moore et al. 2015, p. 79) by codifying innovative approaches into law, policy and institutions. Scaling up consists of one cross-scale strategy with two approaches: "Policy or legal change efforts. New policy development, partnering, advocacy" (Moore et al. 2015, p. 77). 1. Shifting "work to higher levels in government in order to address root causes in larger-scale institutions" (Moore et al. 2015, p. 79) that affect an entire population. This often entails "leaving behind the initial innovative initiative, and starting an entirely new initiative focused on policy change" (Moore et al. 2015, p. 79). 2. Linking "together community-level policy interventions into a more coherent movement" (Moore et al. 2015, p. 79).

\section{Scaling deep}

To impact cultural roots. This is based "on the recognition that culture plays a powerful role in shifting problem-domains, and change must be deeply rooted in people, relationships, communities and cultures" (Moore et al. 2015, p. 77). Scaling deep consists of two strategies: 1. "Spreading big cultural ideas and reframing stories to change beliefs and norms. Intensively share knowledge and new practices via learning communities, distributed learning platforms and participatory approaches" (Moore et al. 2015, p. 77). 2. "Invest in transformative learning, networks and communities of practice" (Moore et al. 2015, p. 77). Learning is "a specific strategy used to build shared mindsets across a range of sectors and organizations, to ensure the impact of [...] initiative is scaled deep into the defining routines and practices and beliefs of partners and collaborators. [...] [L] earning processes [...] can be supported by a range of methods, including: mentorship, deliberate transfer of practices, capturing and sharing organizational or community culture, and shared reflection and evaluation practices" (Moore et al. 2015, p. 80).

\section{Cross-cutting*}

Broaden the problem frame: To adopt "a systems-change perspective" is critical to build "consciousness and intention to change" (Moore et al. 2015, p. 76). This strategy reveals systemic or root causes of problems, leads organizations to re-conceptualize their goals, and enables "organizational leaders to consider different types of scales (e.g. organizational scales, temporal scales, political scales), and to understand the complex interrelated layers of variables and phases of change" (Moore et al. 2015, p. 76).

Seek alternative resources: To find "new funding, or entirely new funding models" because it is "a necessary precursor to scaling" (Moore et al. 2015, p. 76). Build networks and partnerships: To network across sectors is specifically "valuable for focused collaboration, resource-pooling, extending the organization's sphere of influence, and developing unusual alliances." (Moore et al. 2015, p. 75). Networks are also important to generate coherence (Moore et al. 2015).

Seeds of a good Anthropocene

Scale dynamics
Scale up

To "grow to involve more people and places" (www.goodanthropocenes.net).

\section{Scale out}

To reproduce "in different places" (www.goodanthropocenes.net).

\section{Scale deep}

To "change underlying values to inspire people to live in a different way" (www. goodanthropocenes.net).

\section{Outscaling}

To "replicate and disseminate programs, products, ideas or innovative approaches in order to affect more people or to cover a larger geographical area" (Hermans et al. 2016, p. 287).

\section{Upscaling}

To embed or institutionalize "an innovation and changing the 'institutional logics' of 
Table 2 Amplification processes from the different frameworks (*Not used in analysis because this process does not focus specifically on increasing impact) (Continued)

\begin{tabular}{ll}
\hline Framework & Amplification process \\
\hline & an incumbent regime" (Hermans et al. 2016, p. 287). This is done by being concerned \\
& with "identifying opportunities and barriers within institutional structures to properly \\
embed an innovation and the actions that niche actors employ to achieve that, such \\
as creating and fine-tuning technologies, linkage building through intermediation ac- \\
tivities, advocacy and lobbying, mobilizing powerful 'patrons', and creating alternative \\
visions, framings and discourses" (Hermans et al. 2016, p. 287).
\end{tabular}

Acceleration mechanisms

\section{Transition management Deepening}

To learn "as much as possible from a transition experiment" (Rotmans and Loorbach 2008 , p. 27) within a specific context. Learning in deepening "includes (local) shifts in ways of thinking, values and perspectives (culture), shifts in doing things, habits and routines (practices) and shifts in organizing the physical, institutional or economic context (structure). [...] The outcome of deepening is a (local) constellation of culture, practices and structures that fulfills a societal need in a fundamentally different way." (van den Bosch and Rotmans 2008, p. 29-30).

\section{Broadening}

To repeat and link "an experiment in a different context" (Rotmans and Loorbach 2008, p. 27). "What is repeated or linked is the new or deviant constellation of culture, practices and structure, which is the outcome of innovation and learning processes (deepening). [...] The result of broadening can be distinguished in: (1) the new or deviant culture, practices and structure get diffused or adopted in a variety of contexts or (2) the new or deviant culture, practices and structure fulfill a broader function." (van den Bosch and Rotmans 2008, p. 32).

\section{Scaling up}

To "apply a successful experiment at a higher scale level" (Rotmans and Loorbach 2008, p. 27). This means "embedding a transition experiment in -new- dominant ways of thinking (culture), doing (practices) and organizing (structure), at the level of a societal system. [...] The outcomes of scaling up are fundamental changes in the dominant way societal needs are fulfilled, which extend the scale of the initial innovation project." (van den Bosch and Rotmans 2008, p. 33-34).

Strategic niche Growing

To grow means that "[t] he experiment continues and more actors participate, or the scale at which technologies are used increases" (Naber et al. 2017, p. 344).

\section{Replication}

To replicate means that "[t] he main concept of the experiment is replicated in other locations or contexts" (Naber et al. 2017, p. 344).

\section{Accumulation*}

To accumulate means that the "[e] xperiments are linked to other initiatives" (Naber et al. 2017, p. 344).

\section{Transformation}

To transform means that " $[t]$ he experiment shapes wider institutional change in the regime selection environment" (Naber et al. 2017, p. 344). 
3. Scale dynamics research discusses impacts of grassroots innovations across scales enacting transformative change (Hermans et al. 2016). Its purpose is to better understand how grassroots innovations can lead to transformative change across scales and impact beyond their initial context (Hermans et al. 2016). Hermans et al. (2016) describe scaling processes as outscaling and upscaling (Table 2).

4. Acceleration mechanisms research discusses processes that represent means through which transition initiatives can accelerate urban sustainability transitions (Valkering et al. 2017; Gorissen et al. 2018). The objective is to understand how accelerating the accumulation of change and feedback loops in urban sustainability transitions occurs (Gorissen et al. 2018; Ehnert et al. 2018). Gorissen et al. (2018) and Ehnert et al. (2018) describe processes for acceleration as replicating, partnering, upscaling, instrumentalising, and embedding (Table 2).

5. Transition management research discusses processes to increase the impact of transition experiments especially in urban contexts in which small-scale innovations, if successful and combined with others, are tested to move a transition forward (van den Bosch and Rotmans 2008; Loorbach 2010). Rotmans and Loorbach (2008) consider the processes of deepening, broadening, and scaling up to increase the impact of transition experiments (Table 2).

6. Strategic niche management research discusses upscaling processes of transition experiments (Naber et al. 2017). The purpose is to increase the potential of niches to influence regimes (Naber et al. 2017). According to the Multi-Level Perspective (Geels 2002), niches are protective spaces for radical innovations to develop (Smith and Raven 2012), whereas regimes are incumbent socio-technical configurations to realize societal needs (Smith et al. 2010). Naber et al. (2017) describe upscaling processes as growing, replication, accumulation, and transformation (Table 2).

\section{Typology of amplification processes}

To further unpack the commonalities and differences between frameworks, we developed an integrative typology of amplification processes in three steps: identification, comparison, and aggregation of processes. In the first step, we identified in each framework those processes that specifically focused on increasing the impact of sustainability initiatives by analysing the process descriptions (Table 2). Here, we followed Moore et al. (2015), who differentiates between amplification processes and enabling factors. Amplification processes specifically aim to increase impact while enabling factors support this and are relevant across different processes (Moore et al. 2015). Enabling factors are, for instance, cross-cutting, partnering, instrumentalising, and accumulation (Table 2). We excluded these enabling factors from our analysis because they are relevant for all processes (Moore et al. 2015).

In the second step, we compared the identified processes to uncover similarities and differences (Table 2). We found that the frameworks often describe different processes with similar terms and similar processes with different terms. While comparing the different processes, we gained four insights. First, all frameworks share processes aiming to impact more people and places by increasing, for example, the number of sustainability initiatives through new initiatives (i.e., scaling out, scale out, scale up, outscaling, upscaling, replicating, broadening, growing, replication; Table 2). However, the descriptions of these processes differ in level of detail and focus, especially concerning the dependency of new initiatives to existing ones, and the similarity of the context to which 
new initiatives are amplified. Furthermore, some of them contain additional descriptions of other processes that actually focus on the stability of initiatives to have longterm impact (i.e., scale up, upscaling, growing; Table 2). Second, most of the frameworks share processes that aim to impact higher institutional levels (i.e., scaling up, upscaling, embedding, transformation; Table 2). These processes pursue the goal of impacting the societal system by, for instance, changing rules and laws. Third, only the framework of acceleration mechanisms addresses the speed of impact (Gorissen et al. 2018). Fourth, only few frameworks discuss processes that address the change of values and mind-sets (i.e., scaling deep, scale deep, deepening; Table 2).

In the third step and based on the aforementioned comparison, we identified eight generic and unique types of amplification processes (Fig. 2): stabilizing, speeding up, growing, replicating, transferring, spreading, scaling up, and scaling deep. Table 3 shows how each process of the six frameworks is allocated to our eight amplification processes and vice versa. Table S1 provides the exact quotes that we referred to for the allocation (see Additional file 1). It is crucial noting that these processes are not mutually exclusive and that one initiative can deploy diverse processes to increase its impact. In the following, we describe each amplification process and provide examples of initiatives from diverse urban and rural contexts (e.g., social-ecological and socio-technical, Global North and Global South) that illustrate these processes (Table 4 for overview of examples).

We derived stabilizing from processes that mainly focused on prolonging the impact of an initiative (Table 3 and S1). Stabilizing involves strengthening and more deeply embedding initiatives in their context, making them more resilient to up-coming challenges and ensuring that they last longer. This means that initiatives employ actions that capitalize on existing opportunities, increase the number of members, supporters, or users, and also professionalize their practice to ensure a lean procedure and clear

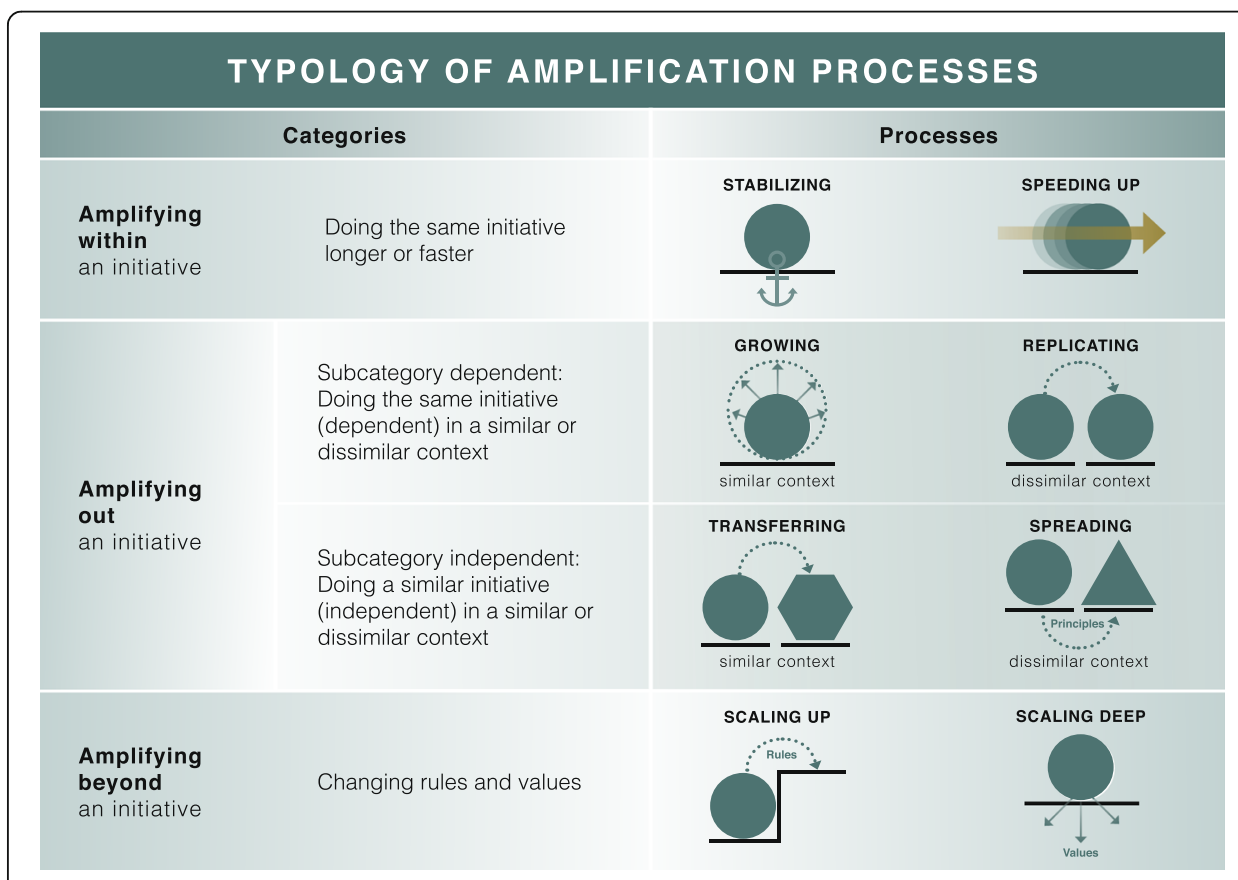

Fig. 2 Illustration of the eight amplification processes grouped into three categories. Note that there is no vertical correspondence between the eight illustrations intended 
Table 3 Overview of how the amplification processes of different frameworks overlap and differ as well as how we grouped them under the amplification processes. We only analysed processes that focus on increasing impact and therefore excluded cross-cutting, partnering, instrumentalising, and accumulation in this analysis (Table 2; ${ }^{*}$ Speeding up is based on the idea of acceleration mechanisms which processes can increase the pace of a transformation. Italics indicate not perfect matches. A more detailed overview of the integration of amplification processes is provided in

Table S1)

\begin{tabular}{|c|c|c|c|c|c|c|}
\hline \multirow{2}{*}{$\begin{array}{l}\text { Amplification } \\
\text { processes }\end{array}$} & \multicolumn{6}{|c|}{ Amplification frameworks } \\
\hline & $\begin{array}{l}\text { Strategies for } \\
\text { social innovation }\end{array}$ & $\begin{array}{l}\text { Seeds of good } \\
\text { Anthropocene }\end{array}$ & $\begin{array}{l}\text { Scale } \\
\text { dynamics }\end{array}$ & $\begin{array}{l}\text { Acceleration } \\
\text { mechanisms }\end{array}$ & $\begin{array}{l}\text { Transition } \\
\text { management }\end{array}$ & $\begin{array}{l}\text { Strategic niche } \\
\text { management }\end{array}$ \\
\hline Stabilizing & & Scale up & & Upscaling & & Growing \\
\hline Speeding up & & & & ${ }^{*}$ all processes & & \\
\hline Growing & & Scale up & Outscaling & Upscaling & & Growing \\
\hline Replicating & Scaling out & Scale out & Outscaling & & Broadening & \\
\hline Transferring & & & & Replicating & Broadening & Replication \\
\hline Spreading & Scaling out & & & Replicating & Broadening & Replication \\
\hline Scaling up & Scaling up & & Upscaling & Embedding & Scaling up & Transformation \\
\hline Scaling deep & Scaling deep & Scale deep & & & Deepening & \\
\hline
\end{tabular}

communication of purpose and mission (Bennett et al. 2016; Valkering et al. 2017; Gorissen et al. 2018). One example is the Alam Sehat Lestari (ASRI) organization (www. alamsehatlestari.org), an Indonesian non-governmental organization in West Kalimantan, whose name means "healthy nature everlasting". ASRI stabilized its impact by involving and getting support from communities and organizations around the Gunung Palung National Park to assist the conservation and reforestation programs. ASRI also facilitated knowledge sharing about sustainable farming and secured the support from other non-governmental organizations (e.g., Health in Harmony; www.healthinharmony.org) and universities to increase ASRI's capacity to adapt to new challenges (Shetty 2009; Pohnan et al. 2015).

Speeding up is based on the framework acceleration mechanisms which aims to accelerate transformations (Gorissen et al. 2018; Ehnert et al. 2018). Although none of the processes from the frameworks specifically addressed the speed of impact as such, speeding $u p$ is important because current sustainability challenges demand faster impact of initiatives. Speeding up involves increasing the pace by which initiatives create impact or are brought to fruition (Frantzeskaki et al. 2017; Valkering et al. 2017; Gorissen et al. 2018). The aim is that initiatives create change faster, for example, by increasing the efficiency of organisational or implementation procedures to have more impact over time (Rosenthal et al. 2017). The role of time and pace with regards to impact of initiatives is essential because current sustainability challenges (e.g., climate change and biodiversity loss) require immediate and fast actions to avoid irreversible change (Olsson 2017). One example is Alberta's Unleashing Local Capital initiative, which provides capital to finance local business development and foster community ownership in urban and rural contexts (www. acca.coop/unleashing). The Unleashing Local Capital initiative was restructured after a first evaluation to increase the efficiency of procedures. This restructuring led to speed up the procedures from proposal to investment to impact (Gismondi et al. 2015).

We derived growing, replicating, transferring, and spreading from processes that seek to impact more people and places, often by increasing the impact range or number of 
Table 4 Overview of examples that illustrate the amplification processes. For each example, we describe what the impact is and how it is amplified

\begin{tabular}{|c|c|c|}
\hline $\begin{array}{l}\text { Amplification } \\
\text { processes }\end{array}$ & Example & What is the impact and what is amplified? \\
\hline Stabilizing & $\begin{array}{l}\text { Alam Sehar Lestari, non-governmental } \\
\text { organization in Indonesia }\end{array}$ & $\begin{array}{l}\text { - Impact: Restoring forest areas and reducing } \\
\text { illegal logging in Gunung Palung National } \\
\text { Park in West Kalimantan, Indonesia. } \\
\text { - Amplification: Stabilizing impact through } \\
\text { getting support from communities and other } \\
\text { organizations. }\end{array}$ \\
\hline Speeding up & $\begin{array}{l}\text { Unleashing Local Capital, local financing } \\
\text { program from Alberta Community and Co- } \\
\text { Operative Association in Canada }\end{array}$ & $\begin{array}{l}\text { - Impact: Providing capital to finance local } \\
\text { business development and foster community } \\
\text { ownership. } \\
\text { - Amplification: Speeding up impact through } \\
\text { restructuring processes to provide capital } \\
\text { faster after submitting proposals. }\end{array}$ \\
\hline \multirow[t]{2}{*}{ Growing } & $\begin{array}{l}\text { Public Lighting Authority, state-created author- } \\
\text { ity in the city of Detroit, U.S.A }\end{array}$ & $\begin{array}{l}\text { - Impact: Providing LED street lights to the } \\
\text { whole City of Detroit. } \\
\text { - Amplification: Growing of impact by installing } \\
\text { LED street lights in the whole City of Detroit } \\
\text { from } 2014 \text { until } 2017 \text {. } \\
\text { - Similar context: Socio-technical context (LED } \\
\text { street lights) and geographical context (City } \\
\text { of Detroit) did not change. }\end{array}$ \\
\hline & Slow Food Italy, food movement in Italy & $\begin{array}{l}\text { - Impact: Promoting local food cultures and } \\
\text { traditions through locally acting groups. } \\
\text { - Amplification: Growing of movement through } \\
\text { establishing more than } 290 \text { locally acting } \\
\text { groups. } \\
\text { - Similar context: Socio-cultural context (Italy) } \\
\text { did not change. }\end{array}$ \\
\hline \multirow[t]{2}{*}{ Replicating } & $\begin{array}{l}\text { The Nature Conservancy, global non- } \\
\text { governmental organization }\end{array}$ & $\begin{array}{l}\text { - Impact: Protecting ecologically-valuable land. } \\
\text { - Amplification: Replicating local chapters to } \\
\text { different countries and states with place- } \\
\text { based missions. } \\
\text { - Dissimilar context: Socio-ecological context } \\
\text { (ecosystems) changed. }\end{array}$ \\
\hline & Alnatura, organic grocery store in Germany & $\begin{array}{l}\text { - Impact: Providing organic local food } \\
\text { products. } \\
\text { - Amplification: Replicating stores to different } \\
\text { cities in Germany. } \\
\text { - Dissimilar context: Socio-economic context } \\
\text { (locally produced food) changed. }\end{array}$ \\
\hline \multirow[t]{2}{*}{ Transferring } & $\begin{array}{l}\text { Water-independent house concept, Tucson, } \\
\text { Arizona, U.S.A. }\end{array}$ & $\begin{array}{l}\text { - Impact: Reducing water demand from houses } \\
\text { in cities. } \\
\text { - Amplification: Transferring the concept from } \\
\text { Tucson, Arizona to Phoenix. } \\
\text { - Similar context: Socio-technical context } \\
\text { (water-independent house concept) did not } \\
\text { change. }\end{array}$ \\
\hline & $\begin{array}{l}\text { Ciclovía, car-free city initiative in Bogotá, } \\
\text { Colombia }\end{array}$ & $\begin{array}{l}\text { - Impact: Providing car-free streets in cities for } \\
\text { the public, especially cyclists. } \\
\text { - Amplification: Transferring of the initiative to } \\
\text { more than } 100 \text { cities. } \\
\text { - Similar context: Socio-cultural context (car- } \\
\text { free streets in cities) did not change. }\end{array}$ \\
\hline Spreading & $\begin{array}{l}\text { Transition Town Network, global network of } \\
\text { transition initiatives }\end{array}$ & $\begin{array}{l}\text { - Impact: Supporting communities to } \\
\text { reimagine and rebuild their cities, villages or } \\
\text { districts. } \\
\text { - Amplification: Spreading of key principles to } \\
\text { different communities all over the world. } \\
\text { - Dissimilar context: Context to which the key } \\
\text { principles are applied changed. }\end{array}$ \\
\hline Scaling up & $\begin{array}{l}\text { Planned Lifetime Advocacy Network, family- } \\
\text { led charitable organization in Canada }\end{array}$ & $\begin{array}{l}\text { - Impact: Supporting parents of children with } \\
\text { disabilities to provide a good life and future }\end{array}$ \\
\hline
\end{tabular}


Table 4 Overview of examples that illustrate the amplification processes. For each example, we describe what the impact is and how it is amplified (Continued)

\begin{tabular}{|c|c|c|}
\hline $\begin{array}{l}\text { Amplification } \\
\text { processes }\end{array}$ & Example & What is the impact and what is amplified? \\
\hline & & $\begin{array}{l}\text { for their children. } \\
\text { - Amplification: Changing financial regulations } \\
\text { concerning savings and benefits for people } \\
\text { with disabilities. }\end{array}$ \\
\hline & $\begin{array}{l}\text { Ciclovía, car-free city initiative in Bogotá, } \\
\text { Colombia }\end{array}$ & $\begin{array}{l}\text { - Impact: Providing car-free streets in cities for } \\
\text { the public, especially cyclists. } \\
\text { - Amplification: Becoming an official program } \\
\text { of the city government. }\end{array}$ \\
\hline \multirow[t]{2}{*}{ Scaling deep } & Time banks, United Kingdom & $\begin{array}{l}\text { - Impact: Providing services in communities. } \\
\text { - Amplification: Changing values through } \\
\text { increasing social inclusion in communities by } \\
\text { promoting reciprocal altruism. }\end{array}$ \\
\hline & City-community initiative in Burgas, Bulgaria & $\begin{array}{l}\text { - Impact: Renaturation of city districts. } \\
\text { - Amplification: Regarding nature as a solution } \\
\text { instead of a risk in the context of urban flood } \\
\text { protection. }\end{array}$ \\
\hline
\end{tabular}

initiatives (Table 3 and S1). These four processes are characterised by two aspects (Fig. 2): (1) the dependency of the amplification (e.g., new initiative elsewhere) to the existing initiative and (2) the similarity of the context to which an initiative has been amplified. A new initiative is dependent when it, for instance, belongs to the existing initiative (e.g., an initiative opening another office in another city). The context to which an initiative is amplified is similar, when essential social, ecological, political or technical structures and dynamics do not substantially differ between the old and new contexts. The relevant context of an initiative is characterised by the type of initiative. For example, the relevant context of a green energy initiative can be the access to technology (Zemp et al. 2011; Lutz et al. 2017); whilst the relevant context for an initiative that aims to promote locally and sustainably produced food can be the food system.

Growing entails the expansion of the impact range (Bennett et al. 2016; Naber et al. 2017). Here, an initiative works in the same way across a geographical location, organization, or sector. As a result of a growing process, an initiative covers more of its potential impact range by reaching out with its program, product, solution or service, or by opening affiliates which are dependent on the existing initiative. One example is the City of Detroit becoming the first large city in the U.S.A. to deliver $100 \%$ public lighting through energy-saving LED lights. The growing process took 3 years from 2014 to 2017 within the socio-technical context of providing public lighting in the geographical context of Detroit (www.pladetroit.org). Another example is the growth of the Slow Food movement in Italy, which is now a global grassroots organization that supports local food cultures and traditions, provides an alternative to hectic life styles, and fights people's decreasing interest in the food they eat (Chaudhury and Albinsson 2015). Since its foundation in 1989, Slow Food grew to a movement with more than 290 locally acting groups ('convivas') in the socio-cultural context of Italy. The 'convivas' are dependent to each other through the coordination and support by Slow Food Italy on the national level (www.slowfood.com). The expansion of Slow Food beyond Italy does not fall under the amplification process growing but refers to transferring (see below). 
Replicating involves the copying of an initiative to a dissimilar context (Moore et al. 2015; Hermans et al. 2016; Bennett et al. 2016; Naber et al. 2017). One example is the branch structure of The Nature Conservancy (TNC), which allows TNC to act responsively in different local contexts dependent on a centrally coordinated conservation strategy (Dees et al. 2004). Another example from TNC is its land acquisition program as a principal tool to conserve nature in different parts of the world. Through this program, TNC identifies ecologically valuable land in different social-ecological contexts, conducts professional appraisals, and publicly markets the property in order to find conservation-minded buyers. TNC has supported to protect 21 million acres in the U.S.A. and approximately 103 million acres globally (www.nature.org). Another example for replicating is the rise of the German organic grocery store chain Alnatura in urban contexts (e.g., Hamburg or Munich) where each new local store is dependent on the headquarters, but functions in dissimilar socio-economic contexts, which means sourcing different locally produced products. Alnatura opened the first store in Mannheim in 1987 and replicated after 30 years 125 stores all over Germany (www.alnatura. de).

Transferring involves taking an initiative and implementing a similar but independent one in a different place, adapted to the new but similar local context (Rotmans and Loorbach 2008; Withycombe Keeler et al. 2016). In comparison to the growing process, a similar but independent initiative emerges. One example is the transfer of a waterindependent house concept from Tucson (Arizona, U.S.A.) to Phoenix (Arizona, U.S.A.), a similar socio-technical context (Forrest et al. 2020). Another example is the transfer of the Ciclovía initiative of Bogotá in Colombia, which offers car-free corridors on Sundays and holidays for cyclists and runners in urban contexts (Zieff et al. 2013). Ciclovía was transferred to more than 100 cities around the world through the Open Streets Project, initiating more than 100 independent initiatives in similar sociocultural contexts (www.openstreetsproject.org).

Spreading involves disseminating core principles and approaches to other places with a dissimilar context (Rotmans and Loorbach 2008; Moore et al. 2015). In comparison to replicating, a similar but independent initiative emerges, that is informed by principles or approaches from an existing initiative. One example for spreading is the Transition Town Network disseminating its principles through a website, publications, and personal exchange to inspire local transition initiatives globally (Feola and Butt 2017). The transition initiatives share the same principles (Hopkins 2008); however, they conduct different and independent projects which are strongly adapted to their social, ecological, political or technical context (Shawki 2013).

We derived scaling up from processes that aim to impact higher institutional levels by changing the rules or logics of incumbent regimes (Table 3 and S1). This means codifying the impact of initiatives into law, policy, or institutions by, for instance, advocacy, lobbying, networking, or supporting alternative visions and discourses (Rotmans and Loorbach 2008; Moore et al. 2015; Hermans et al. 2016; Naber et al. 2017). One example is the work of the Planned Lifetime Advocacy Network (PLAN) in Canada (Moore et al. 2015). PLAN is a family-led charitable organization founded by parents of children with disabilities. PLAN's work led to a Registered Disabilities Savings Plan for people with disabilities to avoid financial state dependency (Moore et al. 2015). Another example is the Ciclovía initiative (see above) as it started in Bogotá in the early 1970s 
through the efforts of cycle activists and became an official program of the city government in 1982 (Díaz del Castillo et al. 2011).

We derived scaling deep from processes that address the change of values and mindsets (Table 3 and S1). Scaling deep aims to change people's values, norms, and beliefs through the work of the initiative by fostering new mind-sets, changing perceptions, and introducing new ways of relating and knowing as well as new value systems (Rotmans and Loorbach 2008; Moore et al. 2015; Bennett et al. 2016; Loorbach et al. 2017; HorceaMilcu et al. 2019). An example are time banks in the United Kingdom where people earn a time credit for the time they spent helping another person. The accrued credits are, in turn, spent on services received from other members of the time bank (Seyfang 2004). Time banks increase social inclusion in communities by promoting reciprocal altruism and provide an alternative way to value work within the hegemonic understanding of work and welfare (Seyfang 2004; Bellotti et al. 2013). Another example is the citycommunity initiative from the city of Burgas, Bulgaria, in which citizens together with the city unsealed soil and planted trees as a nature-based solution for urban flood protection (Frantzeskaki 2019). By introducing nature-based solutions and by including citizens into urban planning, nature can be recognized as a source of solutions instead of a risk.

To reduce the complexity of amplification processes, we aggregated the eight processes in three categories based on their underlying rationale: amplifying within, amplifying out, and amplifying beyond (Fig. 2). Amplifying within consists of processes which generally seek to increase the impact of one specific initiative by, for instance, stabilizing its existence (i.e., prolonging impact) or speeding up the way it impacts (i.e., accelerate impact). Amplifying out consists of processes, which generally seek to increase the impact of initiatives by involving more people and places through a greater impact range and a higher number of initiatives. We use the dependency of the amplification (e.g., new initiative) to the existing initiative to divide amplifying out into two subcategories (Fig. 2). The first subcategory (amplifying out dependent) refers to processes that create initiatives, which are dependent on existing ones. This subcategory includes growing, when an existing initiative's impact range increases in a similar context, and replicating, when the existing initiative is replicated in a dissimilar context. The second subcategory (amplifying out independent) refers to processes that create independent initiatives either by transferring an initiative to another place with a similar context, or by spreading the principles of an existing initiative to a similar initiative in another place with a dissimilar context. Amplifying beyond consists of processes that generally seek to increase their impact by scaling up to reach higher institutional levels or by scaling deep to change values. Processes of amplifying beyond are different from the other categories in that they suggest a reconsideration of how initiatives create impact.

\section{Relevance of the typology}

Our typology serves to integrate existing literature on amplification processes from sustainability transformations research. We hope this will (1) bring more coherence into the dispersed literature on such processes, (2) encourage dialog across research areas to support reflection on these processes, and (3) be of practical assistance to sustainability initiatives in striving to increase their transformative impact by exploring the spectrum of amplification processes. 
First, with our typology we aspire to bring more coherence into the dispersed literature by aggregating the different amplification processes discussed into three categories (i.e., amplifying within, amplifying out, amplifying beyond). This reveals that amplification includes increasing the impact range and number of initiatives in urban or rural contexts (amplifying out), the stabilization and acceleration of impact (amplifying within), and rethinking how initiatives create impact (amplifying beyond). Furthermore, the typology disentangles the different amplification processes grouped under amplifying out (i.e., growing, replicating, transferring, spreading) based on the dependency of new initiatives to existing initiatives, and the similarity of the context to which new initiatives are amplified to. The variety of processes grouped under amplifying out indicates that most studies assume that more initiatives will foster transformations. This assumption mirrors orientations derived from modernist and growth-centred paradigms, which are often found in the discussion on scaling technological innovations. Yet, recent literature highlights a need to leave this perspective behind through processes that change institutional structures, values, or mind-sets (i.e., amplifying beyond) (Olsson et al. 2017). These insights add clarity across research areas on how initiatives in urban and rural contexts can amplify their impact to foster sustainability transformations and can inform future creation of new initiatives that have an amplification purpose. These can also guide future research development about the drivers, barriers, mechanisms, and institutions required for sustainability initiatives to amplify their impact.

Second, this typology considers diverse ideas regarding amplification by integrating existing work from three research areas. It provides a common language for amplification processes that can facilitate dialogue between scholars of different research areas, potentially helping to enable inter- and transdisciplinary collaborations. In our review, we realized that a big share of current work focuses on increasing the range and number of sustainability initiatives in urban or rural contexts (i.e., growing, replicating, transferring, spreading) and impacting higher institutional levels (i.e., scaling up). However, less studies describe how the impact of initiatives can be stabilized or accelerated (i.e., stabilizing, speeding up) or how initiatives can change values and mind-sets (i.e., scaling deep). Therefore, our typology also contributes to rethink which processes require more attention in future research.

Third, our typology can provide guidance for the design of urban and rural sustainability initiatives that have an amplification purpose. For example, to foster large-scale systemic change, most probably a combination of different amplification processes is needed, some of which are more suitable to perform in the beginning (e.g., stabilizing, replicating) and some require a more advanced development of an initiative or even a new initiative (i.e., scaling up) (Moore et al. 2015). Designing initiatives which target system-wide sustainability problems need to take into account challenges and requirements of future amplification (Ghiron et al. 2014).

\section{Considerations and limitations}

Amplification of impact from promising sustainability initiatives are complex, nonlinear, context-specific, and place-based processes, which may even lead to negative, unanticipated, social and environmental side effects, such as bad labour conditions, environmental degradation, or reduction of diversity which increases vulnerability (Leach et al. 2012; Gee et al. 2013; Olsson et al. 2017). Therefore, we consider amplification of 
impact not per se as positive or negative, nor do we claim that the processes described apply to all contexts and places. For example, some processes stem from frameworks that focused only on either urban or rural contexts (Gorissen et al. 2018) and most of the reviewed frameworks stem from research conducted in the Global North. Future research needs to show how applicable our insights are for research on transformations in the Global South, especially in contexts of indigenous peoples and local communities as they may have different understandings of amplification and transformations (Lam et al. 2020).

Amplification entails considerable responsibility challenges, for instance, with regard to anticipating positive and negative outcomes, responding to societal needs and concerns expressed by different stakeholders, being reflexive and adaptive to changing circumstances and contexts, and being inclusive in terms of collaboration and who benefits (Wigboldus et al. 2016). Furthermore, amplification poses questions of power and justice. For instance, it should take into account procedural justice: Who has the power to foster change and decide the direction of change? (Avelino and Rotmans 2011; Boonstra 2016); Who has the ability and responsibility to revoke initiatives that have been amplified and caused negative effects? (Wigboldus et al. 2016); Or who selects which initiatives should be amplified? In addition, amplification of initiatives should also deal with distributive justice by reflecting on who will benefit and lose if initiatives get amplified. For example, one contested sustainability initiative in terms of justice is the production of biofuels and its undesirable impacts on food security and equity of often marginalized actors (Tilman et al. 2009; Blaber-Wegg et al. 2015; Renzaho et al. 2017).

The typology has some limitations, for instance, as it represents a snapshot of current literature, it contains overlaps between processes, and it might miss other processes. Due to the dispersed literature on processes that specifically aim to foster transformations, we did not conduct an exhaustive systematic review, but we selectively reviewed those frameworks from different research areas that target sustainability transformations. Furthermore, we do not regard our amplification processes as completely excluding each other, especially with regard to the processes of amplifying out. Here, the processes described in the literature often seemed overlapping, but we tried to make differences clear (i.e., dependence of the new initiative on the existing initiative and the similarity of the context). Due to our selection of amplification frameworks, our typology might miss other processes, but we are confident that we have covered the ones most dominantly discussed in the scientific literature at the moment.

\section{Future research}

Future research should focus on (1) in-depth understandings of less explored amplification processes, (2) interactions and consequences of processes, (3) differences of amplifying initiatives in urban or rural contexts, and (4) skills and agency of actors.

First, we need to further investigate amplification processes that are less covered in the scientific literature, especially which aim to achieve greater speed of impact (speeding up) and to change values and mind-sets (scaling deep). Accelerating the impact of sustainability initiatives is of high importance (e.g., through more efficiency), because research highlights the need to act with greater speed against sustainability challenges to not cross any points of no return (e.g., climate change, biodiversity loss) (Rockström 
et al. 2009; Russill and Nyssa 2009; Smith et al. 2016; Olsson et al. 2017). Investigating how initiatives can change or activate values and mind-sets is of interest because it is one way to target deep leverage points (i.e., places to intervene in systems) which can lead to fundamental transformations of systems (Meadows 1999; Abson et al. 2017; Horcea-Milcu et al. 2019).

Second, research needs to investigate the interactions and consequences of amplification processes. Knowing which combinations (i.e., which processes together) and sequences (i.e., which processes when in time) of processes are most supportive for transformations can help initiatives to amplify their impact and to better design new urban or rural initiatives that have an amplification purpose (Moore et al. 2014; Moore et al. 2015). Investigating the consequences of processes, such as long-term, cross-scale (e.g., institutional, temporal, or spatial) and domain (e.g., agriculture and labour conditions) effects could unravel unanticipated and undesired outcomes (Moore and Westley 2011).

Third, our typology builds on amplification frameworks that focus on initiatives in urban and rural contexts fostering sustainability transformations. Future research may investigate which processes and which combinations of processes are more or less applied by initiatives that exist and have impact in either urban or rural contexts, or in both. Furthermore, it would be interesting to investigate how initiatives from urban contexts amplify their impact to rural contexts and vice versa, for instance, via processes of amplifying out or amplifying beyond.

Finally, it is important to investigate which skills and agency actors need to pursue amplification processes drawing from the discussions on agency from the different research areas. Building up on resilience and social innovations literature, it is interesting to explore the skills that actors need for different processes and during different phases of sustainability initiatives (Moore et al. 2015). Examples for skills are cultural skills (e.g., visioning, framing, motivating), leveraging and brokering skills (e.g., identifying windows of opportunity, networking, connecting ideas and resources), and politicalinteractional skills (e.g., coalition forming, bargaining, leveraging resources) (Westley et al. 2013). It is necessary to understand how skills for amplification processes are connected to the notions of transformative agency, distributed agency, and system entrepreneurship (Riddell 2013; Westley et al. 2013; Olsson 2017). Connecting to discussions in the sustainability transitions literature, it is interesting to explore the different roles that actors can play (e.g., from the lens of intermediaries), which values drive them, and how they build alliances to foster transformative change (de Haan and Rotmans 2018; Kivimaa et al. 2019).

\section{Conclusion}

Based on a literature review, we developed a typology of amplification processes to increase the impact of sustainability initiatives that exist in urban or rural contexts. Amplification processes are stabilizing, speeding up, growing, replicating, transferring, spreading, scaling up, and scaling deep. We aggregated amplification processes into three categories: amplifying within, amplifying out, and amplifying beyond an initiative. This typology integrates work on amplification processes across different research areas and from studies in urban and rural contexts to unveil how different frameworks working on sustainability transformations conceptualize amplification. Our typology of amplification processes views amplification as threefold: Increasing the impact (1) by 
prolonging or accelerating the impact of one specific initiative (amplifying within), (2) by impacting more people and places (amplifying out), and (3) by changing how initiatives create impact (amplifying beyond). We believe that our typology can stimulate the debate on amplification, by bringing coherence into the dispersed literature on amplification processes, encouraging dialogue across research areas to support reflection on amplification processes, and being of practical use for sustainability initiatives. Scientists and non-academic actors could benefit from this typology in enhancing dialogues, coordinating efforts, and eventually increasing the impact of sustainability initiatives to foster urban and rural transformations.

\section{Supplementary information}

Supplementary information accompanies this paper at https://doi.org/10.1186/s42854-020-00007-9.

Additional file 1: Scaling the impact of sustainability initiatives: a typology of amplification processes.

Abbreviations

ASRI: Alam Sehat Lestari; PLAN: Planned Lifetime Advocacy Network; TNC: The Nature Conservancy; U.S.A.: United States of America

\section{Acknowledgements}

We thank two anonymous reviewers and the editor for their critical and insightful comments which helped substantially to improve the manuscript. We thank David J. Abson, Klara J. Winkler, and Stefan Partelow for their constructive comments on earlier drafts of the manuscript. This research is supported by the Volkswagenstiftung and the Niedersächsisches Ministerium für Wissenschaft und Kultur (Grant Number A112269). This research draws on work undertaken in a large transdisciplinary research project (Leverage Points for Sustainability Transformation). The author(s) acknowledge and thank all project members for their ideas and input in the early stages of this work, even where they are not listed as authors. Full details of project members and their research are available at https:// leveragepoints.org. David P. M. Lam has also been supported by a research fellowship granted by the Foundation of German Business (sdw). Niki Frantzeskaki was also supported by the ARTS Project (Accelerating and Rescaling Sustainability Transitions) funded by the European Union's Seventh Framework Programme (FP7) (Grant number 603654). Arnim Wiek and Daniel J. Lang gratefully acknowledge funding from the Niedersächsisches Ministerium für Wissenschaft und Kultur and the Volkswagenstiftung in line with the research project "Bridging the Great Divide" (Grant number WWN3188).

\section{Authors' contributions}

D.P.M.L. and D.J.L. developed the original idea for the paper. D.J.L. and B.M.L. designed the research. D.P.M.L. and B.M.L. led the review and analysis. A.W. contributed shaping the structure of the paper. A.W., E.M.B., N.F. and A.I.H.M. contributed conceptual and empirical insights. All authors contributed to writing the manuscript and perspectives on developing the typology, drawing from their experience with transformations research.

\section{Authors' information}

David P. M. Lam is a Ph.D. Student at the Institute for Ethics and Transdisciplinary Sustainability Research (IETSR) at Leuphana University Lüneburg, Germany. His research focuses on amplification processes that increase the impact of sustainability initiatives from local actors, and the role of indigenous and local knowledge in sustainability transformations.

Berta Martín-López is Junior Professor in Sustainability Science in the Institute of Ethics and Transdisciplinary Sustainability Research (IETSR) at the Leuphana University of Lüneburg. With a PhD in Ecology and Environmental Sciences, and many years of undertaking applied research, Berta focuses her research on understanding and analysing the dynamics of social-ecological systems at different scales. She is member of the Scientific Steering Committee of the Programme for Ecosystem Change and Society (PECS) and she is actively engaged in the Intergovernmental Platform on Biodiversity and Ecosystem Services (IPBES).

Arnim Wiek is a Full Professor in the School of Sustainability at Arizona State University. His research group develops, tests, and evaluates transformational solutions to sustainability challenges, currently focusing on food economies and enterprises. To support implementation efforts, the group collaborates with businesses, government agencies, nonprofit organizations, and citizens. Prof. Wiek had research and teaching engagements at the Swiss Federal Institute of Technology Zurich, Switzerland, the University of British Columbia, Canada, the University of Tokyo, Japan, Leuphana University of Lüneburg, Germany, and Utrecht University, the Netherlands.

Elena M. Bennett is an Associate Professor at McGill University. Her research interests include social-ecological systems, ecosystem services, and landscape multifunctionality. Her address is 21111 Lakeshore Rd., Ste-Anne-de-Bellevue, QC H9X3V9.

Niki Frantzeskaki is Professor on Urban Sustainability Transitions and Director of the Centre for Urban Transitions at Swinburne University of Technology, Melbourne, Australia. Niki has published close to 100 peer-reviewed articles and in 2017 and 2018 released three books on urban sustainability transitions. She has also edited 13 special issues in topranked journals about sustainability and sustainability transitions. She is coordinating research on environmental governance, and urban sustainability transitions by leading and being involved in a portfolio of research projects with 
research institutes across Europe, Canada, Brazil and Australia. She is actively contributing as an author in CBO, GEO-5, GEO-6 and IPBES assessments.

Andra-loana Horcea-Milcu is a postdoctoral researcher in the Helsinki Institute of Sustainability Science, University of Helsinki. With a background in exploring social-ecological systems and experience in place-based transdisciplinary research, she is interested in leveraging the transformative potential of knowledge co-creation in real-world contexts. Her main focus is on the role of held and assigned values in underpinning such knowledge. Through her boundary work, she aspires to contribute to managing the science|society interface, and to reframing sustainability in terms of core human values.

Daniel J. Lang is Professor for Trandisciplinary Sustainability Research at Leuphana University Lueneburg at the Faculty of Sustainability since January 2010. He was Dean of this faculty between 2012 and 2016 . Since 2016 he is the President's Special Advisor for Sustainability at Leuphana. The main focus of Daniel's work revolves around the further development of the theoretical, methodological as well as process-related foundations of Sustainability Science. In particular his professorship focuses on cooperation and mutual learning processes between different scientific disciplines as well as science and society with the aim to develop robust solution options for urgent sustainability problems of the twenty-first century.

\section{Funding}

None.

Availability of data and materials

The dataset supporting the conclusions of this article is included within the article and its additional file 1.

\section{Consent for publication}

The enclosed paper has not been published, nor submitted for publication, in any other journal or book. All the named authors have approved the content of the paper, its submission to, and publication in your journal. All people entitled to be named as authors are named as such.

\section{Competing interests}

\section{None.}

\section{Author details}

${ }^{1}$ Institute for Ethics and Transdisciplinary Sustainability Research, Faculty of Sustainability, Leuphana University Lüneburg, Universitätsallee 1, 21335 Lüneburg, Germany. ${ }^{2}$ School of Sustainability, Arizona State University, PO Box 875502, Tempe, AZ 85287-5502, USA. ${ }^{3}$ Center for Global Sustainability and Cultural Transformation, Arizona State University, Tempe, AZ, USA. ${ }^{4}$ Leuphana University Lüneburg, Lüneburg, Germany. ${ }^{5}$ Department of Natural Resource Sciences and McGill School of Environment, McGill University, 21111 Lakeshore Road, Sainte-Anne-de-Bellevue, Montreal, Quebec H9X 3V9, Canada. ${ }^{6}$ Centre for Urban Transitions, Swinburne University of Technology, Melbourne, Australia. ${ }^{7}$ Ecosystems and Environment Research Program, Faculty of Biological and Environmental Sciences, University of Helsinki, Helsinki, Finland. ${ }^{8}$ Helsinki Institute for Sustainability Science (HELSUS), University of Helsinki, Helsinki, Finland. ${ }^{9}$ Department of Economics and Management, Faculty of Agriculture and Forestry Sciences, University of Helsinki, Helsinki, Finland.

Received: 27 March 2019 Accepted: 22 April 2020

\section{Published online: 14 May 2020}

\section{References}

Abson DJ, Fischer J, Leventon J, Newig J, Schomerus T, Vilsmaier U, von Wehrden H, Abernethy P, Ives CD, Jager NW, Lang

DJ (2017) Leverage points for sustainability transformation. Ambio 46:30-39. https://doi.org/https://doi.org/10.1007/ s13280-016-0800-y.

Arksey H, O'Malley L (2005) Scoping studies: towards a methodological framework. Int I Soc Res Methodol Theory Pract 8:1932. https://doi.org/https://doi.org/10.1080/1364557032000119616.

Avelino F, Rotmans J (2011) A dynamic conceptualization of power for sustainability research. J Clean Prod 19:796-804 https://doi.org/https://doi.org/10.1016/j.jclepro.2010.11.012.

Avelino F, Wittmayer JM, Pel B, Weaver P, Dumitru A, Haxeltine A, Kemp R, Jørgensen MS, Bauler T, Ruijsink S, O'Riordan T (2019) Transformative social innovation and (dis)empowerment. Technol Forecast Soc Change 145:195-206 . https://doi. org/https://doi.org/10.1016/j.techfore.2017.05.002.

Bellotti V, Carroll JM, Han K (2013) Random acts of kindness: the intelligent and context-aware future of reciprocal altruism and community collaboration. 2013 Int Conf Collab Technol Syst 1-12 . https://doi.org/https://doi.org/10.1109/CTS.2013. 6567197.

Bennett EM, Solan M, Biggs R, McPhearson T, Norström A V, Olsson P, Pereira L, Peterson GD, Raudsepp-Hearne C, Biermann F, Carpenter SR, Ellis EC, Hichert T, Galaz V, Lahsen M, Milkoreit M, Martin-López B, Nicholas KA, Preiser R, Vince G, Vervoort JM, Xu J (2016) Bright spots: seeds of a good Anthropocene. Front Ecol Environ 14:441-448 . https://doi.org/ https://doi.org/10.1002/fee.1309.

Berkes F, Colding J, Folke C, editors. Navigating social-ecological systems: building resilience for complexity and change. Cambridge: Cambridge University Press; 2003.

Berkes F, Folke C, Colding J, editors. Linking social and ecological systems: management practices and social mechanisms for building resilience. Cambridge: Cambridge University Press; 2000.

Blaber-Wegg T, Hodbod J, Tomei J (2015) Incorporating equity into sustainability assessments of biofuels. Curr Opin Environ Sustain 14:180-186 . https://doi.org/https://doi.org/10.1016/j.cosust.2015.05.006.

Blythe J, Silver J, Evans L, Armitage D, Bennett NJ, Moore M-L, Morrison TH, Brown K (2018) The dark side of transformation: latent risks in contemporary sustainability discourse. Antipode 50:1206-1223. https:/doi.org/https:/doi.org/10.1111/anti.12405. 
Boonstra WJ (2016) Conceptualizing power to study social-ecological interactions. Ecol Soc 21:art21. https://doi.org/https:// doi.org/10.5751/ES-07966-210121.

Caniglia G, Schäpke N, Lang DJ, Abson DJ, Luederitz C, Wiek A, Laubichler MD, Gralla F, von Wehrden H (2017) Experiments and evidence in sustainability science: a typology. J Clean Prod 169:39-47 . https://doi.org/https://doi.org/10.1016/j.jclepro.2017.05.164.

Cash DW, Adger WN, Berkes F, Garden P, Lebel L, Olsson P, Pritchard L, Young O (2006) Scale and cross-scale dynamics: governance and information in a multilevel world. Ecol Soc 11:art8 . https://doi.org/http://www.ecologyandsociety.org/ vol11/iss2/art8/

Chaudhury SR, Albinsson PA (2015) Citizen-consumer oriented practices in naturalistic Foodways: the case of the slow food movement. J Macromark 35:36-52 . https://doi.org/https://doi.org/10.1177/0276146714534264.

Cumming DHM. Living off 'biodiversity': whose land, whose resources and where? Environ Dev Econ. 1999;4:220-3.

de Haan FJ, Rotmans J (2018) A proposed theoretical framework for actors in transformative change. Technol Forecast Soc Change 128:275-286. https://doi.org/https://doi.org/10.1016/j.techfore.2017.12.017.

Dees G, Anderson BB, Wei-Skillern J. Scaling social impact: strategies for spreading social innovations. Stanford Soc Innov Rev. 2004; $1: 24-32$.

Díaz del Castillo A, Sarmiento OL, Reis RS, Brownson RC (2011) Translating evidence to policy: urban interventions and physical activity promotion in Bogotá, Colombia and Curitiba, Brazil. Transl Behav Med 1:350-360 . https://doi.org/https:// doi.org/10.1007/s13142-011-0038-y.

Ehnert F, Frantzeskaki N, Barnes J, Borgström S, Gorissen L, Kern F, Strenchock L, Egermann M (2018) The acceleration of urban sustainability transitions: a comparison of Brighton, Budapest, Dresden, Genk, and Stockholm. Sustainability 10:612 . https://doi.org/https://doi.org/10.3390/su10030612.

Feola G (2015) Societal transformation in response to global environmental change: a review of emerging concepts. Ambio 44:376-390 . https://doi.org/https://doi.org/10.1007/s13280-014-0582-z.

Feola G, Butt A (2017) The diffusion of grassroots innovations for sustainability in Italy and Great Britain: an exploratory spatial data analysis. Geogr J 183:16-33 . https://doi.org/https://doi.org/10.1111/geoj.12153.

Forrest N, Stein Z, Wiek A (2020) Transferability and scalability of sustainable urban water solutions-A case study from the Colorado River Basin. Resour Conserv Recycl 157:104790. https://doi.org/10.1016/j.resconrec.2020.104790.

Frantzeskaki N (2019) Seven lessons for planning nature-based solutions in cities. Environ Sci Pol 93:101-111 . https://doi.org/ https://doi.org/10.1016/j.envsci.2018.12.033.

Frantzeskaki N, Borgström S, Gorissen L, Egermann M, Ehnert F. Nature-based solutions accelerating urban sustainability transitions in cities: lessons from Dresden, Genk and Stockholm cities. In: Kabisch N, Korn H, Stadler J, Bonn A, editors. Nature-based solutions to climate change adaptation in urban areas: linkages between science, Policy and Practice. Cham: Springer; 2017. p. 65-88.

Frantzeskaki N, Dumitru A, Anguelovski I, Avelino F, Bach M, Best B, Binder C, Barnes J, Carrus G, Egermann M, Haxeltine A, Moore M-L, Mira RG, Loorbach D, Uzzell D, Omann I, Olsson P, Silvestri G, Stedman R, Wittmayer J, Durrant R, Rauschmayer F (2016) Elucidating the changing roles of civil society in urban sustainability transitions. Curr Opin Environ Sustain 22:41-50 . https://doi.org/https://doi.org/10.1016/j.cosust.2017.04.008.

Frantzeskaki N, Hölscher K, Bach M, Avelino F, editors. Cocreating sustainable urban futures. Cham: Springer; 2018.

Gee D, Grandjean P, van denHove S, MacGarvin M, Martin J, Nielsen G, Quist D, Stanners D, editors. Late lessons from early warnings: science, precaution, innovation. Copenhagen: European Environment Agency; 2013.

Geels FW (2002) Technological transitions as evolutionary reconfiguration processes: a multi-level perspective and a casestudy. Res Policy 31:1257-1274 . https://doi.org/https://doi.org/10.1016/S0048-7333(02)00062-8.

Geels FW, Kern F, Fuchs G, Hinderer N, Kungl G, Mylan J, Neukirch M, Wassermann S (2016) The enactment of socio-technical transition pathways: a reformulated typology and a comparative multi-level analysis of the German and UK low-carbon electricity transitions (1990-2014). Res Policy 45:896-913 . https://doi.org/https://doi.org/10.1016/j.respol.2016.01.015.

Geels FW, Schot J (2007) Typology of sociotechnical transition pathways. Res Policy 36:399-417 . https://doi.org/https://doi. org/10.1016/j.respol.2007.01.003.

Ghiron L, Shillingi L, Kabiswa C, Ogonda G, Omimo A, Ntabona A, Simmons R, Fajans P (2014) Beginning with sustainable scale up in mind: initial results from a population, health and environment project in East Africa. Reprod Health Matters 22:84-92 . https://doi.org/https://doi.org/10.1016/S0968-8080(14)43761-3.

Gismondi M, Marois J, Straith D. 'Unleashing local capital': scaling cooperative local investing practices. In: Kennedy EH, Cohen MJ, Krogman NT, editors. Putting sustainability into practice: applications and advances in research on sustainable consumption. Massachusetts: Edward Elgar Publishing; 2015. p. 204-28.

Gorissen L, Spira F, Meynaerts E, Valkering P, Frantzeskaki N (2018) Moving towards systemic change? Investigating acceleration dynamics of urban sustainability transitions in the Belgian City of Genk. J Clean Prod 173:171-185 . https:// doi.org/https://doi.org/10.1016/j.jclepro.2016.12.052.

Greenhalgh T, Robert G, Macfarlane F, Bate P, Kyriakidou O (2004) Diffusion of innovations in service organizations: systematic review and recommendations. Milbank Q 82:581-629. https://doi.org/https://doi.org/10.1111/j.0887-378X.2004.00325.x.

Grin J, Rotmans J, Schot J, editors. Transitions to sustainable development: new directions in the study of long term transformative change. New York: Routledge; 2010.

Gunderson LH, Holling CS, editors. Panarchy: understanding transformations in human and natural systems, 2nd edn. Washington, DC: Island Press; 2002.

Hermans F, Roep D, Klerkx L (2016) Scale dynamics of grassroots innovations through parallel pathways of transformative change. Ecol Econ 130:285-295. https://doi.org/https://doi.org/10.1016/j.ecolecon.2016.07.011.

Hölscher K, Wittmayer JM, Loorbach D (2018) Transition versus transformation: What's the difference? Environ Innov Soc Transitions 27:1-3 . https://doi.org/https://doi.org/10.1016/j.eist.2017.10.007.

Hopkins R, editor. The transition handbook: from oil dependency to local resilience. Cambridge: UIT Cambridge Ltd.; 2008.

Horcea-Milcu A-I, Abson DJ, Apetrei Cl, Duse IA, Freeth R, Riechers M, Lam DPM, Dorninger C, Lang DJ (2019) Values in transformational sustainability science: four perspectives for change. Sustain Sci 14:1425-1437 . https://doi.org/https://doi. org/10.1007/s11625-019-00656-1.

Horcea-Milcu A-I, Martín-López B, Lam DPM, Lang DJ (2020) Research pathways to foster transformation: linking sustainability science and social-ecological systems research. Ecol Soc 25:art13 . https://doi.org/https://doi.org/10.5751/ES-11332-250113. 
Kivimaa P, Boon W, Hyysalo S, Klerkx L (2019) Towards a typology of intermediaries in sustainability transitions: a systematic review and a research agenda. Res Policy 48:1062-1075 . https://doi.org/https://doi.org/10.1016/j.respol.2018.10.006.

Köhler J, Geels FW, Kern F, Markard J, Onsongo E, Wieczorek A, Alkemade F, Avelino F, Bergek A, Boons F, Fünfschilling L, Hess D, Holtz G, Hyysalo S, Jenkins K, Kivimaa P, Martiskainen M, McMeekin A, Mühlemeier MS, Nykvist B, Pel B, Raven R, Rohracher H, Sandén B, Schot J, Sovacool B, Turnheim B, Welch D, Wells P (2019) An agenda for sustainability transitions research: state of the art and future directions. Environ Innov Soc Transitions 31:1-32 . https://doi.org/https://doi.org/10. 1016/j.eist.2019.01.004.

Kothari A, Demaria F, Acosta A (2014) Buen Vivir, degrowth and ecological Swaraj: alternatives to sustainable development and the green economy. Development 57:362-375 . https://doi.org/https://doi.org/10.1057/dev.2015.24.

Lam DPM, Hinz E, Lang DJ, Tengö M, von Wehrden H, Martín-López B (2020) Indigenous and local knowledge in sustainability transformations research: a literature review. Ecol Soc 25:art3 . https://doi.org/https://doi.org/10.5751/ES11305-250103.

Lam DPM, Horcea-Milcu Al, Fischer J, Peukert D, Lang DJ (2019) Three principles for co-designing sustainability intervention strategies: experiences from southern Transylvania. Ambio 1-15 . https://doi.org/https://doi.org/10.1007/s13280-01901302-x.

Leach M, Rockström J, Raskin P, Scoones I, Stirling AC, Smith A, Thompson J, Millstone E, Ely A, Arond E, Folke C, Olsson P (2012) Transforming innovation for sustainability. Ecol Soc 17:art11 . https://doi.org/https://doi.org/10.5751/ES-04933170211.

Loorbach D (2010) Transition Management for Sustainable Development: a prescriptive, complexity-based governance framework. Governance 23:161-183 . https://doi.org/https://doi.org/10.1111/j.1468-0491.2009.01471.x.

Loorbach D, Frantzeskaki N, Avelino F (2017) Sustainability transitions research: transforming science and practice for societal change. Annu Rev Environ Resour 42:599-626 . https://doi.org/https://doi.org/10.1146/annurev-environ-102014-021340.

Lutz L, Lang D, von Wehrden H (2017) Facilitating regional energy transition strategies: toward a typology of regions. Sustainability 9:1560 . https://doi.org/https://doi.org/10.3390/su9091560.

Mays N, Roberts E, Popay J. Synthesising research evidence. In: Fulop N, Allen P, Clarke A, Black N, editors. Studying the organisation and delivery of health services: research methods. 1st ed. New York: Routledge; 2001. p. 188-220.

Meadows DH. Leverage points: places to intervene in a system. Hartland: The Sustainability Institute; 1999.

Moore M-L, Riddell D, Vocisano D (2015) Scaling out, scaling up, scaling deep: strategies of non-profits in advancing systemic social innovation. J Corp Citizsh 2015:67-84 . https://doi.org/https://doi.org/10.9774/GLEAF.4700.2015.ju.00009.

Moore M-L, Tjornbo O, Enfors E, Knapp C, Hodbod J, Baggio JA, Norström A, Olsson P, Biggs D (2014) Studying the complexity of change: toward an analytical framework for understanding deliberate social-ecological transformations. Ecol Soc 19:art54 . https://doi.org/https://doi.org/10.5751/ES-06966-190454.

Moore ML, Westley F (2011) Surmountable chasms: networks and social innovation for resilient systems. Ecol Soc 16:art5 . https://doi.org/http://www.ecologyandsociety.org/vol16/iss1/art5/.

Naber R, Raven R, Kouw M, Dassen T (2017) Scaling up sustainable energy innovations. Energy Policy 110:342-354 . https:// doi.org/https://doi.org/10.1016/j.enpol.2017.07.056

Olsson P. Synthesis: agency and opportunity. In: Westley FR, McGowan K, Tjörnbo O, editors. the Evolution of social innovation. Cheltenham, UK; Northampton, MA, USA: Edward Elgar publishing; 2017. p. 58-72

Olsson P, Galaz V, Boonstra WJ (2014) Sustainability transformations: a resilience perspective. Ecol Soc 19:art1 . https://doi.org/ https://doi.org/10.5751/ES-06799-190401.

Olsson P, Moore M-L, Westley FR, McCarthy DDP (2017) The concept of the Anthropocene as a game-changer: a new context for social innovation and transformations to sustainability. Ecol Soc 22:art31 . https://doi.org/https://doi.org/10. 5751/ES-09310-220231.

Patterson J, Schulz K, Vervoort J, van der Hel S, Widerberg O, Adler C, Hurlbert M, Anderton K, Sethi M, Barau A (2017) Exploring the governance and politics of transformations towards sustainability. Environ Innov Soc Transitions 24:1-16. https://doi.org/https://doi.org/10.1016/j.eist.2016.09.001.

Pereira L, Frantzeskaki N, Hebinck A, Charli-Joseph L, Drimie S, Dyer M, Eakin H, Galafassi D, Karpouzoglou T, Marshall F, Moore M-L, Olsson P, Siqueiros-García JM, van Zwanenberg P, Vervoort JM (2020) Transformative spaces in the making: key lessons from nine cases in the global south. Sustain Sci 15:161-178. https://doi.org/https://doi.org/10.1007/s11625019-00749-x.

Pereira L, Karpouzoglou T, Doshi S, Frantzeskaki N (2015) Organising a safe space for navigating social-ecological transformations to sustainability. Int J Environ Res Public Health 12:6027-6044 . https://doi.org/https://doi.org/10.3390/ ijerph120606027.

Pereira LM, Bennett E, Biggs R (Oonsie), Peterson G, McPhearson T, Norström A, Olsson P, Preiser R, Raudsepp-Hearne C, Vervoort J (2018) Seeds of the future in the present. In: Elmqvist T, Bai X, Frantzeskaki N, Griffith C, Maddox D, Mcphearson T, Parnell S, Romero-Lankao P, Simon D, Watkins M (eds) the urban planet: knowledge towards sustainable cities. Cambridge University Press, Cambridge, pp 327-350.

Pohnan E, Ompusunggu H, Webb C (2015) Does tree planting change minds? Assessing the use of community participation in reforestation to address illegal logging in West Kalimantan. Trop Conserv Sci 8:45-57 . https://doi.org/https://doi.org/ https://doi.org/10.1177/194008291500800107.

Ramos-Mejía M, Franco-Garcia M-L, Jauregui-Becker JM (2018) Sustainability transitions in the developing world: challenges of socio-technical transformations unfolding in contexts of poverty. Environ Sci Pol 84:217-223 . https://doi.org/https://doi. org/10.1016/j.envsci.2017.03.010.

Raskin P, Banuri T, Gallopín G, Gutman P, Hammond A, Kates RW, Swart R. The great transition: the promise and lure of the times ahead. Boston: Stockholm Environment Institute; 2002.

Renzaho AMN, Kamara JK, Toole M (2017) Biofuel production and its impact on food security in low and middle income countries: implications for the post-2015 sustainable development goals. Renew Sust Energ Rev 78:503-516 . https://doi. org/https://doi.org/10.1016/j.rser.2017.04.072.

Riddell D. BRING ON THE R/EVOLUTION: integral theory and THE challenges of social transformation and sustainability. J Integr Theory Pract. 2013;8:126-45. 
Rockström J, Steffen W, Noone K, Persson Å, Chapin FS, Lambin E, Lenton TM, Scheffer M, Folke C, Schellnhuber HJ, Nykvist B, De Wit CA, Hughes T, van Der Leeuw S, Rodhe H, Sörlin S, Snyder PK, Costanza R, Svedin U, Falkenmark M, Karlberg L, Corell RW, Fabry VJ, Hansen J, Walker B, Liverman D, Richardson K, Crutzen P, Foley J (2009) Planetary boundaries: exploring the safe operating space for humanity. Ecol Soc 14:art32 . https://doi.org/http://www.ecologyandsociety.org/vol14/iss2/art32/.

Rogers EM. Diffusion of innovations. 5th ed. New York: Free Press; 2003.

Rosenthal J, Balakrishnan K, Bruce N, Chambers D, Graham J, Jack D, Kline L, Masera O, Mehta S, Mercado IR, Neta G, Pattanayak S, Puzzolo E, Petach H, Punturieri A, Rubinstein A, Sage M, Sturke R, Shankar A, Sherr K, Smith K, Yadama G (2017) Implementation science to accelerate clean cooking for public health. Environ Health Perspect 125:A3-A7 . https://doi.org/https://doi.org/10.1289/EHP1018.

Rotmans J, Loorbach D. Transition management: reflexive governance of societal complexity through searching, learning and experimenting. In: van den Bergh JCJM, Bruinsma FR, editors. Managing the transition to renewable energy: theory and practice from local, Regional and Macro Perspectives. Cheltenham, UK and Northampton, MA, USA: Edward Elgar Publishing; 2008. p. 15-46.

Russill C, Nyssa Z (2009) The tipping point trend in climate change communication. Glob Environ Chang 19:336-344 . https:// doi.org/https://doi.org/10.1016/j.gloenvcha.2009.04.001

Scoones I, Stirling A, Abrol D, Atela J, Charli-Joseph L, Eakin H, Ely A, Olsson P, Pereira L, Priya R, van Zwanenberg P, Yang L (2020) Transformations to sustainability: combining structural, systemic and enabling approaches. Curr Opin Environ Sustain https://doi.org/https://doi.org/10.1016/j.cosust.2019.12.004.

Sengers F, Wieczorek AJ, Raven R (2019) Experimenting for sustainability transitions: a systematic literature review. Technol Forecast Soc Change 145:153-164 . https://doi.org/https://doi.org/10.1016/j.techfore.2016.08.031.

Seyfang G (2004) Working outside the box: community currencies, time banks and social inclusion. J Soc Policy 33:49-71 . https://doi.org/https://doi.org/10.1017/S0047279403007232.

Seyfang G, Smith A (2007) Grassroots innovations for sustainable development: towards a new research and policy agenda. Env Polit 16:584-603 . https://doi.org/https://doi.org/10.1080/09644010701419121.

Shawki N (2013) Understanding the transnational diffusion of social movements: an analysis of the U.S. solidarity economy network and transition US. Humanity Soc 37:131-158 . https://doi.org/https://doi.org/10.1177/0160597613481799.

Shetty P (2009) Kinari Webb: saving lives and saving rainforests. Lancet 374:1882. https://doi.org/https://doi.org/10.1016/ S0140-6736(09)62080-8.

Smith A, Raven R (2012) What is protective space? Reconsidering niches in transitions to sustainability. Res Policy 41:10251036 . https://doi.org/https://doi.org/10.1016/j.respol.2011.12.012.

Smith A, Voß J-P, Grin J (2010) Innovation studies and sustainability transitions: the allure of the multi-level perspective and its challenges. Res Policy 39:435-448 . https://doi.org/https://doi.org/10.1016/j.respol.2010.01.023.

Smith BR, Kistruck GM, Cannatelli B (2016) The impact of moral intensity and desire for control on scaling decisions in social entrepreneurship. J Bus Ethics 133:677-689 . https://doi.org/https://doi.org/10.1007/s10551-014-2447-6.

Tilman D, Socolow R, Foley JA, Hill J, Larson E, Lynd L, Pacala S, Reilly J, Searchinger T, Somerville C, Williams R (2009) Beneficial biofuels - the food, energy, and environment Trilemma. Science 325:270-271 . https://doi.org/https://doi.org/ 10.1126/science. 1177970.

Valkering P, Yücel G, Gebetsroither-Geringer E, Markvica K, Meynaerts E, Frantzeskaki N (2017) Accelerating transition dynamics in City regions: a qualitative modeling perspective. Sustainability 9:1254 . https://doi.org/https://doi.org/10.3390/su9071254.

van den Bosch S, Rotmans J (2008) Deepening, broadening and scaling up: a framework for steering transition experiments. Rotterdam.

Walker B, Holling CS, Carpenter SR, Kinzig A (2004) Resilience, adaptability and transformability in social-ecological systems. Ecol Soc 9:art5 . https://doi.org/http://www.ecologyandsociety.org/vol9/iss2/art5/.

Westley F, Antadze N. Making a difference: strategies for scaling social innovation for greater impact. Innov J Public Sect Innov J. 2010;15:1-19.

Westley F, Antadze N, Riddell DJ, Robinson K, Geobey S (2014) Five configurations for scaling up social innovation: case examples of nonprofit organizations from Canada. J Appl Behav Sci 50:234-260 . https://doi.org/https://doi.org/10.1177/ 0021886314532945.

Westley F, Olsson P, Folke C, Homer-Dixon T, Vredenburg H, Loorbach D, Thompson J, Nilsson M, Lambin E, Sendzimir J, Banerjee B, Galaz V, van der Leeuw S (2011) Tipping toward sustainability: emerging pathways of transformation. Ambio 40:762-780. https://doi.org/https://doi.org/10.1007/s13280-011-0186-9.

Westley F, Zimmerman B, Patton M, editors. Getting to maybe: how the world is changed. Toronto: Vintage Canada; 2006

Westley FR, Tjornbo O, Schultz L, Olsson P, Folke C, Crona B, Bodin Ö (2013) A theory of transformative Agency in Linked Social-Ecological Systems. Ecol Soc 18:art27 . https://doi.org/https://doi.org/10.5751/ES-05072-180327.

Wiek A, Lang DJ. Transformational sustainability research methodology. In: Heinrichs H, Martens P, Michelsen G, Wiek A, editors. Sustainability science. Dordrecht: Springer; 2016. p. 31-41.

Wigboldus S, Klerkx L, Leeuwis C, Schut M, Muilerman S, Jochemsen H (2016) Systemic perspectives on scaling agricultural innovations. A review Agron Sustain Dev 36. https://doi.org/https://doi.org/10.1007/s13593-016-0380-z.

Withycombe Keeler L, Wiek A, Lang DJ, Yokohari M, van Breda J, Olsson L, Ness B, Morato J, Segalàs J, Martens P, Bojórquez-Tapia LA, Evans J (2016) Utilizing international networks for accelerating research and learning in transformational sustainability science. Sustain Sci 11:749-762 . https://doi.org/https://doi.org/10.1007/s11625-016-0364-6.

Zemp S, Stauffacher M, Lang DJ, Scholz RW (2011) Classifying railway stations for strategic transport and land use planning: context matters! J Transp Geogr 19:670-679. https://doi.org/https://doi.org/10.1016/j.jtrangeo.2010.08.008.

Zieff SG, Hipp JA, Eyler AA, Kim M-S (2013) Ciclovía initiatives: engaging communities, partners and policymakers along the route to success. J Public Heal Manag Pract 19:S74-S82. https://doi.org/https://doi.org/10.1097/PHH.0b013e3182841982.

\section{Publisher's Note}

Springer Nature remains neutral with regard to jurisdictional claims in published maps and institutional affiliations. 